\title{
Materialidad y santidad: reliquias de ligna crucis en Santiago de Chile, siglos XVII y XVIII*
}

\section{Materiality and the Sacred: Ligna Crucis Relics in Santiago de Chile, I7th and I8th centuries}

DOI: https://doi.org/10.22380/20274688.1408

Recibido: 29 de julio del 2020

JOSEFINA SCHENKE REYES**

Aprobado: 12 de octubre del 2020

\section{R E S U M E N}

Este artículo es una primera aproximación a la fragmentaria presencia de las reliquias en Santiago de Chile durante el periodo colonial, reflejada en documentos conventuales y testamentarios que dan cuenta de una existencia relativamente inactiva de estos restos sagrados, objetos visuales y materiales de intenso contenido sagrado. El texto describe la presencia mayoritaria de ligna crucis y la excepcional aparición de otros restos notables, lo que demuestra que la circulación de reliquias foráneas alcanzó la frontera austral del territorio hispano, en sintonía con el movimiento global de reliquias en el contexto de la Contrarreforma.

* La ponencia que inspiró este artículo se presentó en el VI Seminario Internacional de Arte y Cultura en la Corte: "Redes artísticas y circulación de reliquias en el Mundo Hispánico", organizado por el Instituto Universitario "La Corte en Europa" (IULCE, www.iulce.es) y el Departamento de Historia y Teoría del Arte de la Universidad Autónoma de Madrid.

** Doctora en Historia de la Pontificia Universidad Católica de Chile, máster en Historia del Arte de la Universidad de París-Sorbonne y licenciada en Historia del Arte de la Universidad de Bourgogne. Se desempeña como profesora asistente de la Universidad Adolfo Ibáñez, Santiago de Chile, además de ser investigadora del Centro de Estudios del Patrimonio (CEPA) y directora académica del Magíster en Historia del Arte y Diplomado en Curaduría de la misma institución. Sus áreas de interés son las imágenes religiosas (su recepción y narrativa durante el periodo colonial y temprano republicano en Chile) y las reliquias y relicarios como objetos vinculados a la corporalidad humana, la encarnación de lo santo y las expectativas en relación con la materialidad milagrosa. 
Palabras clave: lignum crucis, reliquias, cristianismo, santidad, virreinatos, Colonia, Santiago de Chile, siglo XVI, siglo XVII, siglo XVIII

\section{$\begin{array}{llllllll}\mathbf{A} & \mathbf{B} & \mathbf{S} & \mathbf{T} & \mathbf{R} & \mathbf{A} & \mathbf{C} & \mathbf{T}\end{array}$}

This paper sketches an interpretive approach to the scarce presence of relics in Santiago de Chile during the Colonial period. Taking stock of conventual sources and of some testamentary dispositions, the article delineates the discreet life that those sacred remains (and their associated visual objects) led within the religious life of the era. Through the prevailing presence of the ligna crucis and the occasional advent of other pious remains, the text unveils the widespread dissemination that foreign relics enjoyed during the Counterreformation, which allowed them even to reach the southern border of the Hispanic Empire.

Keywords: lignum crucis, relics, christianism, santity, Santiago de Chile, 16th century, 17 th century, 18 th century

\section{Introducción}

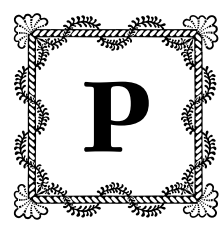

ara I80o, en la iglesia de Nuestra Señora de la Cabeza de la Recolección Franciscana de Santiago de Chile existía un "Altar de Santa María de Cortona" ataviado de "un retablo dorado con una Imagen de la Santa con avito y manto de seda y diadema de plata" (ApFCh, $F R$, "Libro del inventario", I80o, ff. 78 r.-79 r.). Sin embargo, la reliquia de la terciaria canonizada en 1728 (Schenone 565) no estaba allí. En su lugar, se veneraba "una reliquia de lignus Crusis en una custodia de plata de peso un marco puesta en un nicho del Altar" (APFCh, FR, "Libro del inventario", ı80o, ff. 78 r.-79 r.). Fray Francisco Cazanova, un siglo más tarde, tampoco menciona una reliquia de la santa conservada en aquel altar (Cazanova I4I). Por lo tanto, el altar era solo nominal porque, paradojalmente, la reliquia de la santa se conservaba en la iglesia Madre Franciscana de Santiago, más específicamente en la sacristía del convento Máximo de San Francisco, aunque no gozara allí de ninguna veneración documentada. En aquel lugar también se guardaba la authentica de la reliquia, documento que la certificaba como reliquia verdadera, emitido por el obispo Gregorio Alejandro de la diócesis de Cortona en I793, y que además es el único para su tipo del siglo XVIII aún conservado en Chile (APFCh, FAV, "Authentica", vol. 4, f. I82 r.). Las próximas authenticae de reliquias veneradas en Santiago se encuentran documentadas solo a partir de I850. 
Esta reliquia $-\mathrm{y}$ el documento que la autentifica- es una excepción en el escaso panorama de restos santos en el reino de Chile durante el periodo colonial $^{\mathrm{I}}$. Lo anterior porque, en primer lugar, la reliquia de Santa María de Cortona no era simplemente una de contacto, sino una parte del cuerpo de la santa del cual, como ya se dijo, se conserva su authentica. En segundo lugar, el mentado resto santo es representativo del silencio documental que rodea a las reliquias en la ciudad: no existe un registro de un culto específico dirigido a este importante resto corporal. Por último, paradojalmente, el altar dedicado a la santa en dependencias franciscanas recoletas no resguardaba su reliquia, sino que contenía un trozo del madero de la cruz de Cristo (un lignum crucis) que, como se verá, es la reliquia más nombrada por las fuentes de la época en Santiago de Chile.

Un generalizado silencio rodea a las reliquias en la capital de la Capitanía General de Chile, conforme con la documentación colonial consultada hasta ahora, que incluye documentación notarial, administrativa, conventual, sinodal y conciliar ${ }^{2}$. Este silencio se refiere sobre todo a sus usos: pareciera que estos objetos no hubiesen cumplido una función determinada en el espacio público, en procesiones o ceremonias, como sí lo hacían activamente las imágenes. Tampoco fueron las reliquias protagonistas de fiestas de recibimiento, en contraste con lo que sucedió en México con las reliquias que recibieron los jesuitas en 1578 (Fabre 575-593), por ejemplo; ni fueron utilizadas en rogativas como aquellas organizadas contra la peste, siempre en Nueva España (Karnal I2-30; Rubial I3-30).

Por otra parte, la existencia, la proveniencia, los usos y los espacios de culto de estos restos santos no han sido estudiados en Santiago de Chile. Tanto para el periodo virreinal como para el republicano, la historiografía ha hecho caso omiso de estos objetos. La causa de tal situación es, quizás, la desaparición de las reliquias de los espacios sagrados y, en segundo lugar, aquel silencio que las rodea en la documentación colonial conservada de la capitanía general de Chile. Ello sin contar con que estos objetos han desaparecido de los espacios devotos; algunos se conservan en museos y archivos.

I Si bien no toda reliquia poseía una auténtica que la identificara como tal, como queda de manifiesto en los documentos de tipo notarial.

2 No se descarta que en el futuro se puedan encontrar nuevas fuentes que den luces sobre la existencia y el uso de las reliquias en Santiago de Chile. 
Las reliquias forman parte integral del acervo simbólico del culto cristiano, a la par con las imágenes. La presencia de las imágenes y de las reliquias, su contemplación y su veneración, es valorada usualmente como la presencia de la propia persona sagrada desde los orígenes de este tipo de devoción, que se sitúan en el siglo ir con la visita a las tumbas de los mártires. Las reliquias son los restos venerados del cuerpo de un santo y se interpretan analógicamente como el santo mismo, por lo cual las plegarias y el tacto se dirigen a ellas como si se dirigieran al santo en persona. Las reliquias también pueden ser no corporales, llamadas "de contacto": en tal caso, el feligrés interactúa con un trozo de material que ha estado en contacto con él en el curso de su existencia terrena. Una categoría adicional está conformada por las reliquias "representativas": líquidos que emanan de un cuerpo, u objetos o paños que han sido puestos en contacto con los huesos del santo o con su sepulcro, llamados sanctuaria o brandea (Geary; Julia, I085; Schmitt; Herrmann-Mascard).

En este artículo se aborda el tema de la presencia de las reliquias en este espacio de frontera, así como de las escasas excepciones que rompen el silencio de las fuentes documentales consultadas hasta el momento, haciendo hincapié: I) en la circulación de reliquias desde Roma y la distribución en Santiago de Chile; 2) en la preminencia de la aparición de las reliquias de la cruz que nombra la documentación por sobre cualquier otro tipo de reliquia; 3 ) en el testimonio peculiar que rinde la orden franciscana como protagonista del fenómeno relicario en el Santiago de Chile virreinal, por un documento que atestigua la validez de una reliquia y que es copia de un remoto original conservado en Madrid; 4) en la desmembrada y silente presencia de otras reliquias en el ámbito conventual.

\section{Dos momentos contemporáneos: circulación de reliquias desde Roma y distribución en Santiago de Chile}

Este estudio se enmarcará en Santiago de Chile, capital de la capitanía general de Chile, y la ciudad más poblada y central entre las principales de la época en esta región administrativa (las otras eran Concepción, La Serena y Valparaíso). Se dará cuenta a continuación, brevemente, de la condición geográfica, política y eclesial de la ciudad, así como de la contemporánea circulación de reliquias desde Roma hacia el resto del mundo católico. 
Santiago de Chile fue fundada en I54I por el extremeño Pedro de Valdivia, y la Real Audiencia se instituyó allí en I609. La lejanía de Santiago era real y práctica, puesto que se ubicaba al menos a seis meses de viaje desde Espańa y a dos desde Lima o Buenos Aires. La duración del trayecto hasta Santiago de Chile desde el Perú o desde España era considerable (Zúñiga 53-54). Esta distancia era también psicológica: la ciudad precordillerana y cercana al extenso océano Pacífico estaba rodeada de poblados poco significativos y de grandes haciendas. Su situación político-administrativa era la de capital de una capitanía general dependiente del virreinato del Perú, lo que determinaba la condición precaria y "de frontera" que eso traía consigo. Adicionalmente, la guerra de Arauco produjo una frontera infranqueable con el mundo indígena mapuche, límite que se ubicaba aproximadamente a 500 kilómetros al sur de Santiago. La última ciudad de la frontera era Concepción, una urbe cuya función fue ser el último bastión español antes de Valdivia y la isla de Chiloé, ambas al sur de los dominios indígenas y a las que solo se podía acceder por barco. Este límite no sería franqueado sino hasta I883, en plena República, cuando los territorios entre los ríos Biobío y Toltén fueron completamente ocupados por el Estado chileno.

El obispado de Santiago se creó en 156I, abarcando la zona comprendida entre los ríos Copiapó y Maule, más la provincia trasandina de Cuyo, y la primera catedral de Santiago se construyó, en una versión más definitiva, durante el último cuarto del siglo xvi, es decir, tardíamente con respecto a los virreinatos del Perú y México. La realidad agraria de la zona central de Chile contrastaba con la atestada geografía religiosa de la capital durante la Colonia y los numerosos templos que fueron consolidándose durante los siglos XVII y XVIII, dando cuenta de una presencia masiva de conventos e iglesias y sus respectivos sacerdotes regulares y monjas en un espacio urbano relativamente reducido (Araneda 70-7I). Todos estos lugares debieron ser ataviados con imágenes y reliquias para montar el aparato visual y devoto católico. No quedan, sin embargo, mayores rastros de reliquias.

Contemporáneamente, el hecho que inauguró la gran profusión de reliquias durante la Modernidad ocurrió en I578, cuando se descubrió un antiguo cementerio cristiano cerca de la Puerta Salaria del muro aureliano de Roma. A partir del Concilio de Trento, con la reafirmación de la legitimidad del culto a las reliquias, Roma comenzó a distribuir generosamente los tesoros de las catacumbas por todo el espacio de la cristiandad, política que continuó hasta los años I860. La etapa de mayor "extracción" de las catacumbas se sitúa en el siglo XVI (entre 1578 y I590), a pesar de las sucesivas prohibiciones de recuperar 
osamentas de estos cementerios paleocristianos. En I603, bajo el pontificado de Clemente VIII, el cardenal Camillo Borghese, futuro Paolo V, promulgó el primer edicto que prohibía, bajo penas corporales o pecuniarias, el descenso a las catacumbas sin la autorización expresa del mismo sumo pontífice. El pontificado de Paolo V marcó la época de mayor extracción y distribución de las reliquias de las catacumbas durante el siglo Xvir por parte de las autoridades eclesiásticas, puesto que, según un mandato de I6I3, se prohibió su extracción por parte de personas ajenas a las jerarquías de la Iglesia. Tras la profusa dispersión de los restos santos de las catacumbas romanas durante el pontificado de Gregorio XV, en I624 Urbano VIII decidió poner punto final al comercio ilícito de estas reliquias cerrando estos cementerios por decreto, medida poco efectiva, como lo demuestran las sucesivas prohibiciones de Alejandro VII en 1656, durante todo el siglo XVIII, e incluso hasta León XIII en I880 (Julia; Ghilardi I2I-I3I).

Este mismo espacio temporal de la expansión de las reliquias por el mundo católico coincide aproximadamente con la fundación de Santiago de Chile y el periodo virreinal, que concluyó durante la segunda década del siglo xix. De acuerdo con la documentación existente, la historia de las reliquias en Chile se inicia con los franciscanos, puesto que esta orden conserva las primeras dos reliquias recensadas en Santiago de Chile. El cráneo de una de las II.ooo vírgenes y vestigios de Tierra Santa son nombrados por un testimonio muy temprano, de 1584 , redactado por el quinto ministro de la orden franciscana en Chile, fray Francisco Montalbo:

Reliquias que ay en esta casa. Una cabeza delas once mil virgines con su testimonio autorizado y en una caxuela estan muchos pedazos de piedras y palos de la tierra scta. No ay otra reliquia ningu[n]a en toda esta Prov[vinci]a, ni otra cosa notable de que posea esta religión. (APFCh, $F A V$, "Relación”, vol. I, f. I4 v.)

La leyenda de santa Úrsula y las iı.ooo vírgenes masacradas por los hunos bajo los muros de Colonia proviene de la Historia Regum Brittaniae escrita entre II35 y II38 por Geoffroy de Monmouth, quien recoge historias y mitos en torno a numerosos reyes y dinastías. Esta Historia gozó de una gran difusión durante la Edad Media, además de suscitar otras hagiografías paralelas, al igual que las numerosísimas reliquias corporales de estas doncellas mártires. Tales reliquias serían osamentas encontradas a partir de IIo6 en un antiguo cementerio de Colonia con la inscripción "virgo Ursula, muerta a los dieciocho años” (Réau 2, 300-304). El centro de distribución de las reliquias de Úrsula 
y de sus compañeras fue Colonia, desde donde se exportaron a monasterios benedictinos y cistercienses de los Países Bajos, Francia e Italia. Además, los restos de las II.ooo vírgenes sacrificadas junto a santa Úrsula formaban parte de las osamentas sagradas más comunes en las catedrales españolas: el convento de las Descalzas Reales de Madrid contaba con dos cabezas (Vincent-Cassy 695-720; Montgomery).

En este informe redactado a petición de fray Francisco de Gonzaga (ministro general de la orden entre 1579 y I587), Montalbo introdujo sus quejas dirigidas a Roma con respecto a la pobreza de la orden en Chile y a las dificultades del trabajo pastoral. No se especifica la proveniencia directa de los restos conservados en el convento franciscano de Santiago, y el documento al que refiere Montalbo, y que las habría autentificado, ya no existe.

Por otra parte, tanto esta reliquia como los "restos de Tierra Santa" son los únicos de su tipo descritos en algún documento para el Santiago colonial. Los restos de las iı.ooo vírgenes de Colonia pertenecían a uno de los conjuntos de reliquias más prestigiosos, aunque también numerosos, de la cristiandad de la época. Por otra parte, los vestigios de Tierra Santa eran también preciosos. Por lo anterior, resulta llamativo que estos valiosos relicarios descritos por Montalbo no fueran protagonistas de fiestas ni veneración conocidas. Ninguno de los dos vuelve a ser nombrado en las fuentes e inventarios franciscanos conservados.

Otro ejemplo temprano de reliquias en Santiago aparece en la documentación de la orden de san Agustín. Los agustinos conservaron en su iglesia dos reliquias de santos profilácticos y antipestíferos, una de san Sebastián y otra de san Lucas. La primera de ellas es nombrada por primera vez en I608, cuando se manda a pagar "un relicario de ébano con reliquia de S. Sebastian, catorce patacones" (APSA, vol. I, f. 48 r.), y se la nombra también en I6ıo, "un relicario de ébano pequeño con reliquia de San Sebastián” (APSA, vol. I, f. IoI v.). Desde I659 pudo existir una reliquia de san Lucas, puesto que se registra el pago de misas "de extraordinario al predicador de san Lucas, dos reales" (APsA, "Cuentas", vol. 2, f. I3 v.), y este tipo de pagos se detectan hasta entrado el siglo XVIII; por ejemplo, en octubre de I727 y I728 (APSA, "Gastos mensuales", vol. 5, ff. I28 r., I46 r.). No obstante, solo en I80o, en el inventario de bienes de la sacristía e iglesia, se menciona la reliquia de san Lucas, junto a la imagen de san Agustín y de san Juan de Sahagún:

Altar de $\mathrm{N}^{\text {tro }}$ Padre

En el sagrario 
La reliquia de S. Lucas en una urna de plata.

La reliquia de S. Sebastian en latón (APSA, "Inventario de bienes", vol. 8,

f. 176 r.)

Ambas reliquias no reciben un culto específico fuera de la misa de san Lucas, que podría haber protagonizado su reliquia, pero están ubicadas en el altar mayor y en el sagrario, por lo que su función es, fundamentalmente, simbólica.

Otro uso cercano al taumatúrgico se percibe en un relicario cuyo contenido santo no se especifica y que era preservado en el altar de la Virgen del Carmen del hospital San Juan de Dios. Inventariado en 1776, tenía también un uso eucarístico, puesto que servía para llevar la ostia consagrada a los enfermos:

Yt. el altar de nuestra señora deelCarmen y end[ic]ho altar un sag[rari].o y enel colocado el santísimo sacramento que sede posita en dos basos de plata de uno dorado, y un relicario que sirve de dar el beatico a los enfermos con su bolsa aforrado en platta con su cordon de seda y $\mathrm{d}[\mathrm{ic}]$ ho sagrario tiene corp[ora].l un baso dechrisptal con supurificador con cortinas de brocato puerta y llave corriente yunpulpito. (ANHCh, FCG, "Hospital", vol. 966, f. 26I v.)

\section{La omnipresencia de los ligna crucis}

La reliquia de la cruz es el más preciado tesoro entre los instrumentos de la pasión o armas de Cristo (los otros son la Columna de la Flagelación, la Corona de Espinas y los Clavos de la Crucifixión) (Réau 5, 22). Existen numerosos relatos que describen cómo santa Elena, madre de Constantino, habría descubierto la Verdadera Cruz en Jerusalén. Uno de los más antiguos es el de san Ambrosio (año 395), de acuerdo con el cual la santa halló el madero y los clavos en una cisterna del monte Gólgota (Réau 2, 427; De Voragine 363-372). Las reliquias habrían sido entonces trasladadas hasta Constantinopla, donde el obispo Makarios de Jerusalén las presentó al pueblo, además de consagrar la iglesia de la Resurrección (la Anastasis Basilica) (Haustein-Bartsch y Wolf 42). Este descubrimiento de la más preciosa de las reliquias cristianas, y su veneración en la capital, Bizancio, asentó las bases de un imperio recientemente convertido por la decisión de su emperador, en 303, y que necesitaba de un símbolo fuerte para demostrar su adhesión a Cristo. Más tarde, la Vera Cruz se transformó en la reliquia más preciada durante la Edad Media, junto a la Corona de Espinas 
y los Clavos de la Crucifixión. A partir del pontificado del papa Sergio I (607-70I), la fiesta de la Cruz comenzó a celebrarse en Roma.

Poco a poco, aquello que se interpretaba como el madero santo se fue desmembrando y, junto a otros trozos inventados ${ }^{3}$, se fueron repartiendo por toda Europa, en pedazos más o menos importantes, recubiertos de lujosos relicarios en forma de cruz (Frolow; Klein; Hahn). El resto más grande de la Vera Cruz conservado en Espańa es el venerado en el monasterio franciscano de santo Toribio de Liébana, en Cantabria, donde habría llegado en el siglo viII directamente desde Tierra Santa.

No obstante la lejanía de Santiago de Chile de los lugares de distribución de los ligna crucis (literalmente, los "maderos de la Cruz"), este es el tipo de reliquia más común durante los siglos XVII y XVIII en esta ciudad. Las fuentes revelan su presencia tanto en inventarios domésticos como en inventarios de altares de cofradías y de iglesias. En las iglesias — la agustina y la franciscana- formaban parte de las propiedades de la sacristía, es decir, eran objetos utilizados en relación con el altar mayor y en otro tipo de ceremonias; esto último para el caso franciscano.

De acuerdo con la documentación disponible, los agustinos fueron los primeros frailes de Santiago que dispusieron de una valiosa reliquia de la cruz a partir de I623. El inventario de la sacristía de 1598 no la nombra, pero sí el de I623, un documento muy deteriorado, que describe:

Un sagrario aforrado [ilegible, papel deteriorado] [en] que está el Ssmo.

Sacramento [ilegible, papel deteriorado] en que está el lignum [crucis] en damasco colorado. (APSA, RGACS, vol. I, f. 5 r.)

Otra descripción, algunas fojas más adelante, permite comprender la disposición del Santísimo Sacramento y del lignum crucis en la sacristía agustina:

- Otra cajita pequeña chapeada de plata que está en el sagrario del Ssmo Sacramento

- Una cajita pequeña que está en el sagrario del lignum crucis con reliquias de los sanctos. (APSA, RGACS, vol. I, f. I3 v.)

El lugar de la reliquia de la cruz que revela este inventario resulta muy destacable, porque ocupaba un sagrario, al igual que la Eucaristía consagrada.

3 Por "inventados" no me refiero a "imaginados", sino al uso de este término en el ámbito de las reliquias, en relación con la etimología del verbo inventar, del latín invenire: encontrar. 
Esta relación nos parece del mayor interés, puesto que, por la creencia en el proceso de la transubstanciación ocurrido en la consagración del pan y del vino, estos objetos se vuelven "presencias reales", es decir, el verdadero cuerpo y la verdadera sangre de Cristo. Desde un punto de vista de la reliquia como corporalidad santa, se trata de las reliquias más santas y más sagradas. Ella ocupa, a título propio, la custodia, el sagrario, el ostensorio en el altar mayor de la iglesia. Este mismo lugar acogía la reliquia del santo madero, que era presentada y exhibida en un sagrario y se veneraba allí, expuesta a los ojos del fiel, al igual que el Santísimo Sacramento.

Ambos sagrarios - el del Cuerpo de Cristo y el de la Cruz de Cristoeran parte de un conjunto de otros objetos devotos de la sacristía: otro grupo de reliquias, cuyos santos se desconocen, y algunos Agnus Dei ${ }^{4}$; unas "tablas pequeñas, una de las fiestas del año y otra de las indulgencias del Ssmo. Sacramento" (APSA, RGACS, vol. I, 5); los atuendos y joyas de Nuestra Señora de la Gracia y "unas andas de flores de seda y escarchado que sirven al Ssmo. Sacramento con veinticuatro campanillas de plata en el chapitel" (APSA, RGACS, vol. I, f. 9 v.).

En inventarios domésticos del periodo colonial de Santiago de Chile también se mencionan restos reputados de la Cruz. Por ejemplo, en i697, entre los bienes del capitán Andrés de Mendoza y Posada, se nombra:

I relicario de oro que pesa 4 libras, con sus vidrieras de buena fábrica, colocado en el santo lignum crucis, que costó Iooo; I hechura de bulto romana de un redentor crucificado, con su dosel y su velo, avaluado en 60 pesos. (ANHCh, ES, vol. 429, f. 43 r.)

Es interesante notar aquí el precio del relicario: Iooo pesos. Es un precio muy elevado en relación con los 60 pesos atribuidos a la preciada escultura de bulto de un Cristo denominada "romana", es decir, de gusto renacentista, estilo

4 El Agnus Dei consiste en un medallón de cera blanca, de forma oval, que lleva grabada sobre una de sus caras la figura del cordero pascual y por el reverso la efigie de un santo. Producida y distribuida en Roma, la medalla fue acuñada en un molde oblongo a partir de cera derretida procedente de la fusión de cirios pascuales, y cuenta con una bendición del papa. Dado que el medallón está destinado a representar la pureza del cordero pascual, la cera que lo constituye debe pasar por un proceso de purificación que reemplace su tinte amarillento original por "una blancura resplandeciente" (Troyon 69-78). La figura del cordero aparece rodeada por la inscripción eucarística tomada de las palabras del Bautista en el Jordán: Ecce Agnus Dei qui tollitpeccata mundi. Al pie del cordero figura también el nombre del papa que ha bendito el Agnus, con su escudo de armas y una referencia al año de su pontificado. 
considerado más sofisticado que el barroco virreinal andino. Es preciso destacar aquí el valor del relicario y su belleza, a pesar de no ser de uso litúrgico. Es posible pensar que la "experiencia" estética y devota de un relicario doméstico era similar a la experiencia en el ambiente litúrgico que describe Cynthia Hahn:

This beauty is an inalienable and required quality of reliquaries, but rather than being taken for granted as intrinsic to materials or craftsmanship it was actively sought as an experience. (Hahn, "What Do Reliquaries" 3II)

Según los documentos notariales consultados, el único caso en que se nombra la naturaleza de la reliquia en el interior de un relicario es cuando se trata de restos de la Santa Cruz. Todos los demás casos de reliquias o relicarios presentes en inventarios o testamentos domésticos son simplemente enumerados, sin especificar a quién pertenecen los restos santos. Es importante advertir que las reliquias no podían tasarse, por carecer de valor comercial (Geary; Herrmann-Mascard), y el madero santo pertenece a esa categoría de objeto; con todo, es posible que por ser este último la "reliquia de reliquias" y el objeto santo por antonomasia, debiese ser nombrado como tal, incluso en el contexto de un inventario comercial. Además, no debe olvidarse que el relicario por sí mismo sí era tasable. Al observar el inventario de Mendoza, se aprecia un especial cuidado en la descripción del relicario, consignando su peso, la buena hechura de sus vidrios, su reliquia y su importante valor pecuniario. El continente - el relicario- parece estar hecho en función de la dignidad de su contenido. En efecto, el precio del relicario resulta exorbitante si se considera que un esclavo negro podía costar 600 pesos, según otros inventarios contemporáneos consultados. Lo acompaña además un Cristo "romano", dentro de su dosel y tras el velo que lo cubre de las miradas en momentos profanos.

Algo similar sucede en el inventario de los bienes de Josepha Lecaros, de I80o, cuando se describe detalladamente el objeto que contiene a la reliquia, y aquí reliquia y relicario pasan a ser un solo objeto: "I lignum crucis con una cruz de cristal con sus ramitos de filigrana de plata" (anHCh, ES, vol. 949, f. I r.). Esto suele suceder con las reliquias de la Cruz, cuyo contenedor es, a su vez, una cruz 5 . Encontramos aquí que la reliquia potencia la imagen, acentuado por 
el hecho de que el prototipo — el resto santo- se recubre del símbolo material que lo identifica y del que formó parte. El continente - la cruz lujosa- envuelve al contenido (la pequeña astilla de la Vera Cruz), visible tras una vidriera: continente y contenido se funden e identifican ${ }^{6}$.

\section{El prestigioso origen de dos ligna crucis franciscanos}

Como se vio antes, la única authentica conocida del periodo virreinal en Chile certifica la veracidad de los restos de santa Margarita de Cortona. Se trata de un texto que utiliza las habituales expresiones de este tipo de documento: autentifica lo que se ha visto y se supo, lo que se dice y se materializa, con expresiones como "lugares auténticos"; el reconocimiento por parte de la autoridad de las reliquias "como tales"; la emisión de "palabras auténticas" y la materialización del "sello episcopal". Se especifica, además, que son restos extraídos de un "cuerpo perfumado", lo que alude a la calidad santa de la carne muerta pero incorrupta. A continuación, se presenta la traducción al español desde el latín de la authentica de la reliquia de santa Margarita de Cortona (I793):

A todos y cada uno de quienes han de leer estas palabras nuestras, declaramos sin duda alguna y damos fe de que, habiéndose exhibido ante nuestra presencia estas Sagradas Reliquias, las cuales fueron extraídas desde lugares auténticos, las hemos reconocido como tales y las hemos dotado de nuestras palabras auténticas y de nuestro sello [episcopal]; y a continuación extrajimos de ellas algunas partículas que provienen indudablemente del [caligrafía ilegible] cuerpo perfumado de Santa Margarita de Cortona, y no de la mortaja en la cual fue envuelto el cuerpo de esta santa tras las exequias; $y$, para que sean veneradas, pusimos tales partículas en un objeto de plata de figura oval provisto de un cristal en su parte anterior [caligrafía ilegible], el cual fue bien cerrado mediante una cuerda envuelta en seda roja. (A PFCh, FAV, "Authentica", vol. 4, f. I82)

estaban simbólicamente vinculados al poder imperial de Constantinopla, que heredaría Roma y su estado pontifical (Bozoky ir7-133).

6 De especial interés resulta, para una investigación futura, buscar las causas factuales y simbólicas de la presencia de reliquias en el ámbito doméstico. Hasta ahora, no se han encontrado fuentes de origen eclesiástico que hagan alusión a este particular uso como relicario o como joya-relicario. 
Otro modo de autentificar una reliquia era por medio de una carta del donador. Tal es el caso de un documento único para Chile, considerando el silencio de las reliquias al que antes se aludía. El archivo del Convento Mayor de San Francisco de Santiago conserva un documento que revela la existencia y excepcionalmente describe el prestigioso origen y el uso de un lignum crucis. Se trata de una copia de 1869 hecha por el fraile Francisco Cazanova del documento de 1730 de fray Nicolas Freitas que cita, a su vez, otro documento fechado en I7or y firmado por el recoleto de Cartagena (España) Pedro de Jesús. El propósito del fraile Freitas — vicario de la Recoleta para entonces- es atestiguar sobre la autenticidad de las reliquias e incentivar su culto "para que no esté oculta tan gran presea, i se le de la reverencia i adoracion que al mismo Dios se da que es de justicia", (ApfCh, FAV, "Sobre un Lignum Crucis", vol. 3, II7). También insiste en el hecho de que un primer trozo santo dividido generó dos reliquias que se veneran, respectivamente, en el convento Recoleto Franciscano y en el convento Máximo de San Francisco, ambos en Santiago de Chile. Ambos provendrían de un trozo de madera donado por el papa Clemente VIII a Felipe III, y regalado por el franciscano recoleto español Pedro de Jesús a I) Bernardo Garzía y 2) las Descalzas Reales. El primer trozo habría llegado a la recolección franciscana santiaguina y el segundo al convento de San Francisco.

El texto del fraile Nicolás Freitas transcrito en 1869 por Francisco de Cazanova consta de dos partes, en la primera de las cuales Freitas transcribe una carta de Pedro de Jesús (religioso franciscano de la recolección de la provincia de Cartagena), donde este último se refiere a un lignum crucis que le habría sido donado en el interior de una cruz de oro por Juan José de Austria, hijo ilegítimo de Felipe IV, a quien Pedro de Jesús dice haber servido por catorce años. Juan José de Austria habría heredado esta reliquia de su padre quien, a su vez, la habría recibido de Felipe III.

Lo excepcional de este documento del Archivo Franciscano de Santiago de Chile es que parece ser copia de otro documento conservado en Madrid en el archivo del monasterio de las Descalzas Reales del Archivo Real, escrito en 1707 por el mismo Pedro de Jesús (la diferencia de fechas — I70I para el documento santiaguino y 1707 para el madrileńo- podría imputarse a un error por parte de alguno de los dos copistas santiaguinos, Freitas o Cazanova, pero la fecha definitiva sería 1707).

Ambos testimonios confirman que la reliquia del santo madero estaba contenida en una cruz "de un jeme de largo, guarnecida de oro, que la guarnición pesó diez i nueve onzas”, y llevaba inscrita en latín la siguiente leyenda por el reverso: 
Esta Santisima Cruz, o preciosa reliquia, cortó por sus propias manos la Santidad de Clemente Octavo, del Santo leño de la cruz de Jerusalen i las puso en las manos del Cardenal Mendoza protector de Espańa, para que la pusiese en las manos del Señor Rey Don Felipe Tercero. (AR, $P C, F D R$, "Copia de la Authentica", caja 7, exp. 3)

En la comparación de ambos documentos —el madrileño y el santiaguino- - se puede comprobar que hasta aquí el santiaguino copia, casi textualmente, la authentica escrita de puño y letra por el propio Pedro de Jesús y conservada en Madrid. Sin embargo, los documentos difieren en la sección subrayada. En efecto, el documento madrileño consigna que Pedro de Jesús da una porción del madero a "mi Seńora Soror Mariana de la Cruz y Austria", mientras el documento chileno consigna la entrega al "Padre Fr[ay] Bernardo García". A la authentica madrileña se suman las cartas de I708, en las que el fraile franciscano explica a Mariana de la Cruz y Austria las razones por las cuales le entrega parte de esta reliquia. La madre de Carlos II (caída en desgracia después de la muerte de su hijo y el advenimiento de los Borbones en España) fue una importante receptora de reliquias en el convento de las Descalzas Reales de Madrid (Vincent-Cassy 70o). Según otras fuentes, el mismo Pedro de Jesús habría donado otro lignum crucis a la parroquia de Alpera, localidad de Albacete:

Los objetos de arte salvados [de la Guerra Civil] fueron: [...] un grande Signum-Crucis [sic], regalo de don Juan de Austria a fray Pedro Jesús de Alcantarilla de Murcia, y éste regalado al párroco de Alcantarilla, don Pedro Alejandro Villaescusa, el cual lo donó a esta parroquia unida a una gran cruz negra y un relicario de plata, según testamento el día 2 de junio de i749. (Carrión 39I-392)

En el documento chileno, a la carta de Pedro de Jesús le sigue el testimonio de 1730 del recoleto Nicolás Freitas, en el que se relata por medio de qué circulación informal esa reliquia había llegado la casa de los recoletos de los franciscanos de Santiago desde las manos de fray Bernardo García y cómo ella compartía el origen con aquella que se veneraba en el convento de las Descalzas

7 El papa Clemente VIII (pontífice entre 1592 y 1605) fue contemporáneo del cardenal Mendoza, protector de Castilla de 1588 a 1592. Sin embargo, Mendoza no fue contemporáneo del reinado de Felipe III (1598-162I), sino Pedro de Deza, quien sustituyó a Mendoza como protector de Castilla (Bénichou 1027). 
Reales. Mediante los enrevesados testimonios de la circulación de estas reliquias, se hermanan las veneradas por los franciscanos de Santiago de Chile con una de las más importantes colecciones de reliquias españolas (la de las Descalzas Reales de Madrid). Los hermanos de Asís de esta remota capital se integran así a una tradición devota de la Iglesia universal, por tratarse de un pedazo del madero del sacrificio supremo.

Se refleja además en este testimonio la consabida virtud de la reliquia, cuyas sucesivas divisiones no restan en ella sacralidad. Por el contrario, pareciera que esta sacralidad y su prestigio se fundaran en el hecho de provenir de un primer madero y hermanarse devotamente, por partición, con otras astillas sagradas difundidas por el mundo cristiano.

\section{Los usos de los ligna crucis franciscanos}

El valor de este documento radica también en que, además de ser una narración única que busca autentificar una reliquia en Santiago de Chile, describe también cuál era el culto que recibían estos ligna crucis en las iglesias franciscanas.

Se explica el uso de este lignum crucis en la recoleta franciscana:

... El R[everen]do Padre i siervo de Dios Fr[ay] Buenaventura de Zarate [...] en días de comunión festivos que sentaba para las hijas de confesión las hasía que adorasen a este Santísimo Lignum Crucis, diciéndole Este es el Santísimo madero i propio en que fuimos redimidos, en que nuestro Señor Jesucristo Dios i hombre verdadero murió, Y semejantes palabras y con tres adoraciones, su Paternidad i las confesadas, luego que acababan de comulgar, puesta la Santísima reliquia sobre el ara del altar, la adoraban, en su capilla donde decía misa, Y yo lo supe por relacion de las hijas, i lo vi en ocación que fui a la dicha capilla. (APFCH, FAV, “Sobre un Lignum Crucis”, vol. 3, II6-II8)

Y se describe aquí, además, que la reliquia del Convento Mayor de Santiago, que habría sido entregada por la propia María de Austria al fraile Tomás Moreno, salía en procesión los viernes santos. Sin embargo, no existen registros alternativos de estos usos en las fuentes consultadas para Santiago.

La reliquia iba complementada, además, por otra de contacto de un santo franciscano, san Pedro de Alcántara: 
Y dicha Santísima Cruz tiene los brazos del madero en que murió N[uestro] $S$ [eñor] Jesucristo, i los pies son de la iguera del glorioso padre $S[a n]$ Pedro de Alcantara. (APFCh, FAV, "Sobre un Lignum Crucis", vol. 3, II6)

No existen noticias más tardías sobre la reliquia de san Pedro de Alcántara, como si se hubiera olvidado que ella formaba parte de la cruz de la reliquia del lignum crucis. El primer inventario de la iglesia del Convento Máximo de San Francisco es de 1752 y consigna, en la sacristía, "una custodia [de plata] dorada y esmaltada en que está el Sancto Lignum Crucis" y "otra Custodia de orense dorada que está en el Altar de Nuestro Padre San Francisco de la bóveda en que está otra reliquia de el Santo Lignum Crucis" (Ramírez 195). Es decir, un trozo de la cruz continúa en la sacristía y un segundo se dejó en el altar destinado al patriarca ubicado en una bóveda. A estas reliquias se habían sumado en la sacristía, junto al lignum crucis, en I752, una "Custodia [de plata] dorada pequeña en que está la reliquia de Nuestro Padre San Francisco" y "otra Custodia de plata pequeña en que está la reliquia de San Francisco Solano” (Ramírez 195). Ambas reliquias — del santo fundador y del santo franciscano "de América" — son de importancia porque son representativas tanto del origen de la orden como de su actualidad en el nuevo continente ${ }^{8}$. Se desconoce desde cuándo la reliquia de Solano estaba ahí, el santo había sido canonizado hacía ya 26 años.

El inventario de la sacristía de I8I7 revela que la disposición de estos restos santos había variado y se exponían, permanentemente, en el altar mayor:

reliquias laterales al Sagrario, lignum Crucis en custodia de plata dorada; y la de NPS Franco en custodia pequeña de plata dorada otra mas de plata. (Ramírez 200)

Es significativo el lugar que se le daba a este conjunto de reliquias a comienzos del siglo xix: las reliquias se exhibían y se complementaban con la sacralidad del sagrario, como en el caso agustino. Estos dispositivos de relicarios en los altares habían sido desarrollados por los jesuitas desde el siglo XVII, llegando a su paroxismo - en cuanto a cantidad y coherencia devota con las imágenes de los altares- en la iglesia del Colegio de San Miguel de la Compañía de Jesús

8 San Francisco Solano, hermano menor franciscano nacido en Córdoba, fue enviado al Perú en 1589, donde misionó intensamente durante más de veinte años. Luego rigió el convento de Trujillo durante cuatro años, pasó sus últimos días predicando en Lima y murió en I6ro. Fue canonizado por Benedicto XIII en 1726 (Schenone 420-422). 
en 1767 , para vísperas de la Expulsión (Schenke). Los propios jesuitas inventarían, ese mismo año, en el altar de Cristo de la nueva iglesia de la Compañía, "un lignun $[s i c]$ crucis de mas de pulgada de alto y un $s$ [anto] $x r$ [is] to de bronce dorado" (ANHCh, FJCh, "Imbentario", vol. 7, ff. 99 v.-IOo r.).

Una tercera reliquia de la cruz se veneraba en el ámbito franciscano de la Alameda, en las dependencias de la Venerable Orden Tercera. Donada a la hermandad por Isabel de Espinoza, viuda del gobernador Francisco Sánchez de la Barrera, en 1772 (APFCh, FVOT, "Libro de todos los documentos I698-I78I", n. ${ }^{\circ}$ Io, ff. 3 r.-30 v.), esta es la única reliquia recensada para la hermandad de terciarios franciscanos en los inventarios, que describen: "un Santo Christo con peaña de plata una cruz de cristal con su linnum crucis" (APFCh, FVOT, "Libro de Ymbentario [...] de I7I8 hasta el de I783", s. f.). En otro catastro no fechado - aunque de la primera década del XIX — se especifica "una peaña grande forrada en plata, en donde está una cruz de cristal con su cruz de lignum crucis: le faltan dos piezas" (ApFCh, FVOT, "Libro de Ymbentario [...] de i7i8 hasta el de 1783 ”, s. f.). Sucede aquí que el relicario no es una caja, sino una cruz. El contenido precioso es integrado en una cruz de cristal con peańa de plata.

En tanto, en la recolección franciscana, para I80o, la reliquia de la cruz conservaba en el interior de "una urna dorada; con sus vidrios, con dos custodias de plata, en la una, un anus, con linum crucis y en la otra un relicario pequeño con reliquias de los s[an]tos apóstoles" (APFCH, FR, "Libro del Inventario de las alhajas", ff. 78 r.-79 r.). El madero santo se integraba visualmente en un conjunto de reliquias y, como vimos también es el caso en la orden agustina en Santiago, se lo relacionaba con un Agnus Dei. Para esta misma fecha, en el altar recoleto de Santa María de Cortona se veneraba otro lignus crucis, "en una custodia de plata de peso un marco puesta en un nicho del Altar" (APFCh, FR, "Libro del Inventario de las alhajas", ApFch, ff. 78 r.-79 r.).

Es interesante constatar que la reliquias de la Vera Cruz de Cristo existían en el ámbito doméstico, en la iglesia agustina, y se conservaban en mayor y creciente cantidad en el ambiente franciscano en Santiago entre I730 y I8I7, de acuerdo con las fuentes disponibles. En esos años, las reliquias franciscanas, sin contar la de la Orden Tercera, se multiplican en dos. De las dos atestiguadas por el fraile Nicolás Freitas, se llega a cuatro. Quizás las fuentes no revelarán nunca el origen de estos dos nuevos trozos de la Santa Cruz, pero resulta sugerente pensar en la posibilidad de que se tratara de una "partición" de cada pequeño pedazo de lejano origen romano en dos astillas: cada una seguía conteniendo en sí la energía sacra y el significado devoto de la anterior y ejercía también 
como reliquia. El principio consiste en dividir un primer cuerpo u objeto santo hasta lo invisible, y cada porción contiene en sí la santidad del pedazo mayor.

\section{Conclusiones}

Hasta lo que las fuentes revelan, las reliquias, salvo la excepción de un lignum crucis, no gozaron de fiesta conocida ni devoción acentuada en Santiago de Chile, y parece que su función fue otra: permanecer estáticas, ser representativas y simbólicas, cargando de sacralidad los espacios y las imágenes.

Ciertos aislados hallazgos documentales permiten trazar el lugar de las reliquias en Santiago de Chile, si bien figuran como objetos desconectados de relatos y sermones. Por otra parte, los archivos notariales y conventuales dan cuenta de la presencia de estos objetos, pero rara vez de sus proveniencias: mayoritariamente, las fuentes no revelan cómo estos restos santos alcanzaron estas latitudes periféricas y "de frontera”, tanto con respecto al virreinato del Perú como a la metrópoli peninsular y a Roma. En ese sentido, el documento resguardado en el archivo del convento de San Francisco, casi idéntico al conservado en el Archivo Real de España, es a todas luces excepcional.

Otro tipo de silencio rodea también a las reliquias: ellas son, en su mayoría, anónimas. Sobre todo durante el siglo XviII, cuando una profusión de estos objetos se advierte en algunos espacios devotos en Santiago, se desconoce a quiénes pertenecen. Es probable que cada una de ellas contara con su pequeño titulus, pero al menos los inventarios privados o eclesiásticos no especifican el santo del que son originarias. Lo mismo sucede con los inventarios o tasaciones privados, si bien en este caso podríamos atribuir ese silencio al pudor por nombrar un objeto semejante, de tal valor sagrado, pero que, sin embargo, carece de "precio" y avalúo posible, de acuerdo con la tradición medieval. Las reliquias no son objetos transables monetariamente, de ahí la necesidad de la donación de reliquias o de su robo (Geary).

En el ámbito de los templos de las órdenes religiosas asentadas en Santiago de Chile, muchas veces los ligna crucis se los resguardaba en la sacristía, lugar que, en principio, parece privado y fuera de las miradas de los laicos. Sin embargo, los objetos de la sacristía tenían vocación pública porque eran transportados y expuestos en el altar mayor, el centro del templo y de la liturgia. Era allí donde se celebraba el sacrificio de la misa principal del templo y se oficiaba con lo más sagrado, y, por lo tanto, el lugar donde se ubicaban las reliquias 
y las imágenes que materializaban las principales advocaciones de la orden. Estas imágenes eran "contagiadas" visual y emocionalmente por lo sagrado y las reliquias cumplían el mismo papel. Los objetos más valiosos del altar mayor se los resguardaba, por su parte, en la sacristía, aunque estaban en constante uso en las misas. También allí se conservaban objetos valiosos de las cofradías o capillas cuando estas no tenían dónde guardar bajo llave.

En suma, este "silencio" de las reliquias se refiere sobre todo a los orígenes, a la veneración y a la identificación de estos objetos santos, así como a la relevancia de su presencia en espacios de culto. Estamos conscientes del problema que podría suponer hablar de una "ausencia" o "silencio" de las reliquias, puesto que podría tratarse de una mera ausencia en las fuentes, producto de pérdidas. Sin embargo, nos parece elocuente y demostrativo de este fenómeno el hecho de que las imágenes tengan una presencia pública importante, y sirvan de socorro en fiestas, procesiones y rogativas, en tanto que la reliquia se mantenga en reserva en el discurso — salvo contadas excepciones que aquí analizamos-.

\section{6 \\ B I B L I O G R A F í A}

\section{F U E N T ES PRIMARIA S}

\section{Archivo Provincial Franciscanos de Chile (APFCh)}

Fondo Asuntos Varios (FAV)

Fray Francisco Montalbo, "Relación de lo que ay que avisar desta Provincia de la Sanctissima Trinidad de Chile”, I584, vol. I, f. I4 v. A partir de la compilación de estos informes, el general de la orden, fray Luis de Gonzaga publicó en Roma, en I587 y 1602, el texto compilatorio de la situación de la orden seráfica en el mundo, el De origine seraphicae Religionis Franciscanae: eius que progressibus: de Regularis Observanciae institutione: forma administrationis ac legibus admirabilique eius propagatione, Roma, Ex Typographia Dominici Basae, i587 y 1602.

"Sobre un Lignum Crucis", vol. 3, II7-II9.

“Authentica de la reliquia de Santa Margarita de Cortona”, 1793, vol. 4, f. I82.

Fondo Recoleta $(F R)$

"Libro del Inventario de las alhajas y ornamentos de la Iglesia y Sacristía del Convento Santa Recolección de Nuestra Señora de la Cabeza de la Ciudad de Santiago de Chile", I8oo. 
Fondo Venerable Orden Tercera (FVOT)

"Libro de todos los documentos [...] desde [...] I698 hasta [...] I78 I".

"Libro de Ymbentario [...] de 1718 hasta el de 1783 ".

\section{Archivo Provincial de San Agustín de Chile (APSA)}

"Registros de gastos anuales del Convento de Santiago (I595-I625)", (RGACS)

"Inventario de los bienes de la sacristía [...]", vol. I.

"Memoria de las cosas y ornamentos de la sacristía de este convento de Santiago que se hallaron en i6ro", vol. I.

"Memoria de las cosas y ornamentos de la sacristía de este convento de Santiago que se hallaron en 1598 ".

“Cuentas 1659-1677", vol. 2, f. I3 v.

"Gastos mensuales del Convento de Santiago (I727-1730)", vol. 5, ff. I2 8 y I 46.

"Inventario de bienes, sacristía e iglesia", c. I800-I806, vol. 8, Casa grande (Sacristía) (I777-I82I), f. I76.

\section{Archivo Nacional Histórico de Chile (ANHCh)}

Fondo Escribanos de Santiago (ES).

Fondo Jesuitas de Chile (FJCh)

"Imbentario de la Iglesia del Colegio Maximo de San Miguel", vol. 7, Santiago,

I767, ff. 99 v.-IoO.

Fondo Capitania General (FCG)

“Hospital San Juan de Dios", vol. 966, 1776-77, ff. 213-271 v.

\section{Archivo Real (Madrid) (AR)}

Patronatos de la Corona, Fondo Descalzas Reales,. (PC, FDR)

"Copia de la Authentica, o Certificacion que el P. Fr. Pedro de Jesus Religioso de la Orden de N.P.S. Fraco dexo en este Conveto declarando que el santo lignum crucis que dio a la señora sor Mariana de Austria es legítimo y verdadero", caja 7, exp. 3.

\section{I F U E N T E S S E C U N D A R I A S}

Araneda Bravo, Fidel. Historia de la Iglesia en Chile. Santiago de Chile: Ediciones Paulinas, I986.

Bénichou, Léa. "Los cardinales protectores de Castilla bajo el reinado de Felipe III". Familia, cultura material y formas de poder en la España moderna, III Encuentro de Jóvenes Investigadores en Historia Moderna Universidad de Valladolid, editado por Máximo García Fernández. Valladolid: Fundación Española de Historia Moderna, 2015, pp. $1025-1038$. 
Bozoky, Edina. "Le trésor de reliques de l'abbaye de Zwiefalten. Un précieux témoignage des échanges culturels entre Orient et Occident". Les échanges culturels au Moyen Âge, XXXIIe Congrès de la Société des Historiens Médiévistes de l'Enseignement Supérieur Public, Université du Littoral-Côte d'Opale, juin 20o1, París, 2002, pp. I17-133. https:// doi.org/10.3406/shmes.2001.1810

Carrión Íñiguez, José Deogracias. La persecución religiosa en la provincia de Albacete durante la guerra civil (1936-1939). Albacete: Instituto de Estudios Albacetenses, 2004.

Cazanova, Fray Francisco. Historia de la Recoleta. 1875. Santiago de Chile: Publicaciones del Archivo Franciscano, 1998.

De Voragine, Jacques. La Légende Dorée, dirigido por Alain Boureau. París: Gallimard, 2004.

Fabre, Pierre-Antoine. "Reliquias romanas en México: historia de una migración”. Saberes de la conversión: Jesuitas, indígenas e imperios coloniales en las fronteras de la cristiandad, editado por Guillermo Wilde. Buenos Aires: Editorial SB, 201 I, pp. 205-224.

--.. "Reliques romaines à Mexico (I575-1578): Histoire d'une migration”. Reliques romaines: invention et circulation des corps saints des catacombes à l'époque moderne, editado por Stephane Baciocchi y Cristophe Duhamelle. Roma: École Française de Rome, 2016, pp. 575-593.

Frolow, Anatole. Les reliquaires de la Vraie Croix. París: Institut Français d'Études Byzantines, 1965 .

Geary, Peter. Furta sacra: Le vol des reliques au Moyen Âge. París: Aubier, 1993.

Ghilardi, Massimiliano. “'Auertendo, che per l'osseruanza si caminarà con ogni rigore’. Editti seicenteschi contro l'estrazione delle reliquia dalle catacombe romane”. Sanctorum. Rivista dell'associazione per lo studio della santità dei culti e delléagiografia, n. ${ }^{\circ}$, 2005 , pp. I2I-137.

Hahn, Cynthia. "Collector and Saint: Queen Radegund and Devotion to the Relic of the True Cross". Word and Image, vol. 22, 2012, pp. 268-274. https://doi.org/10.1080/02 666286.2006 .10435756

---. “What Do Reliquaries Do for Relics?”. Numen, n. 57, 2010, pp. 284-316. https://doi. org/10.1163/156852710x501324

Haustein-Bartsch, Eva y Norbert Wolf, eds. Icons (Ikonen-Museum, Recklinghausen). Colonia: Taschen, 2008.

Herrmann-Mascard, Nicole. Les reliques des saints, formation coutumière d'un droit. París: Klincksieck, 1975 .

Julia, Dominique. "Reliques". Dictionnaire des faits religieux, dirigido por Régine Azria y Danièle Hervieu-Léger. París: PUf, 2010, p. 1085. 
Karnal, Leandro. "Les reliques dans la conquête de l'Amérique luso-espagnole”. Reliques modernes. Cultes et usages chrétiens des corps saints des réformes aux revolutions, editado por Philippe Boutry, Pierre-Antoine Fabre y Dominique Julia. París: Éditions de l'EHESS, 2009, pp. 731-750.

Klein, Holger A. "Eastern Objects and Western Desires: Relics and Reliquaires between Byzantium and the West”. Dumbarton Oaks Papers, vol. 58, 2004, pp. 283-31 4. https:// doi.org/10.2307/3591389

Montgomery, Scott Bradford. St. Ursule and the Eleven Thousand Virgins of Cologne. Berna: Ilustrada, 20 Io.

Ramírez Rivera, Hugo Rodolfo. "Contribución al estudio de la historia cultural de Chile: el manuscrito inédito Libro Ynventario General de Todas las Officinas del Convento Grande Franciscano de Nuestra Señora del Socorro de Santiago". Anuario de la Historia de la Iglesia en Chile, i. ${ }^{\mathrm{a}}$ parte, ${ }^{\circ}{ }^{\circ}$ I8, 2000 , pp. I8I-210.

Réau, Louis. Iconografía del arte cristiano: Iconografía de los santos. 2 tomos, vols. I y 5. Barcelona: Ediciones del Serbal, 2000.

Rubial García, Antonio. “Cuerpos milagrosos. Creación y culto de las reliquias novohispanas”. Estudios de Historia Novohispana, vol. I8, 1998, pp. 13-30. https://doi.org/10.2220I/ iih.24486922e.1998.018.3473

Schenke, Josefina. "Imágenes, reliquias y devociones en la iglesia del Colegio Máximo de San Miguel; Iconografías, relaciones y funciones (Santiago de Chile, siglo XVIII)”. Revista de Historia Social y de las Mentalidades, vol. i8, n. ${ }^{\circ}$ 2, 201 4, pp. 59-77.

Schenone, Héctor. Iconografía del arte colonial: Los santos. Vols. I y II. Buenos Aires: Fundación Tarea, 1992.

Schmitt, Jean-Claude. "Les reliques et les images". Les reliques: objets, cultes, symboles dans le haut Moyen Age : actes du Colloque international de l'Université du Littoral-Côte d'Opale, editado por Edina Bozoky y Anne-Marie Helvétius. Turnhout: Brepols, I999, pp. I 45-167.

Troyon, Octavien. "Les Agnus Dei. Leur bénédiction à Rome et leurs usages”. Rome, n. ${ }^{\circ}$ 99, I912, pp. 69-78.

Vincent-Cassy, Cécile. "Les reliques des saints des catacombes romaines en Espagne avant et après les Habsbourg. À propos des Déchausées Royales de Madrid”. Reliques romaines: invention et circulation des corps saints des catacombes à l'époque moderne, editado por Stephane Baciocchi y Cristoph Duhamelle. Roma: École Française de Rome, 2016, pp. 695-720.

Zúñiga, Jean-Paul. Espagnols d'outre-mer: émigration, reproduction sociale et mentalités à Santiago-du-Chili, au XVII siècle. París: Éditions de EHESS, 2002. 